Revue des patrimoines

\title{
Eléments de cartographie pour la connaissance de l'architecture balnéaire bauloise
}

Jean-Louis Kerouanton

\section{(2) OpenEdition}

\section{Journals}

Édition électronique

URL : http://journals.openedition.org/insitu/1748

DOI : 10.4000/insitu. 1748

ISSN : 1630-7305

Éditeur

Ministère de la Culture

Référence électronique

Jean-Louis Kerouanton, «Eléments de cartographie pour la connaissance de l'architecture balnéaire bauloise », In Situ [En ligne], 4 | 2004, mis en ligne le 01 mars 2004, consulté le 07 septembre 2020. URL : http://journals.openedition.org/insitu/1748 ; DOI : https://doi.org/10.4000/insitu.1748

Ce document a été généré automatiquement le 7 septembre 2020

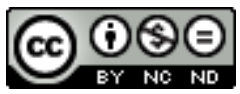

In Situ Revues des patrimoines est mis à disposition selon les termes de la licence Creative Commons Attribution - Pas d'Utilisation Commerciale - Pas de Modification 4.0 International. 


\title{
Eléments de cartographie pour la connaissance de l'architecture balnéaire bauloise
}

\author{
Jean-Louis Kerouanton
}

Figure 1

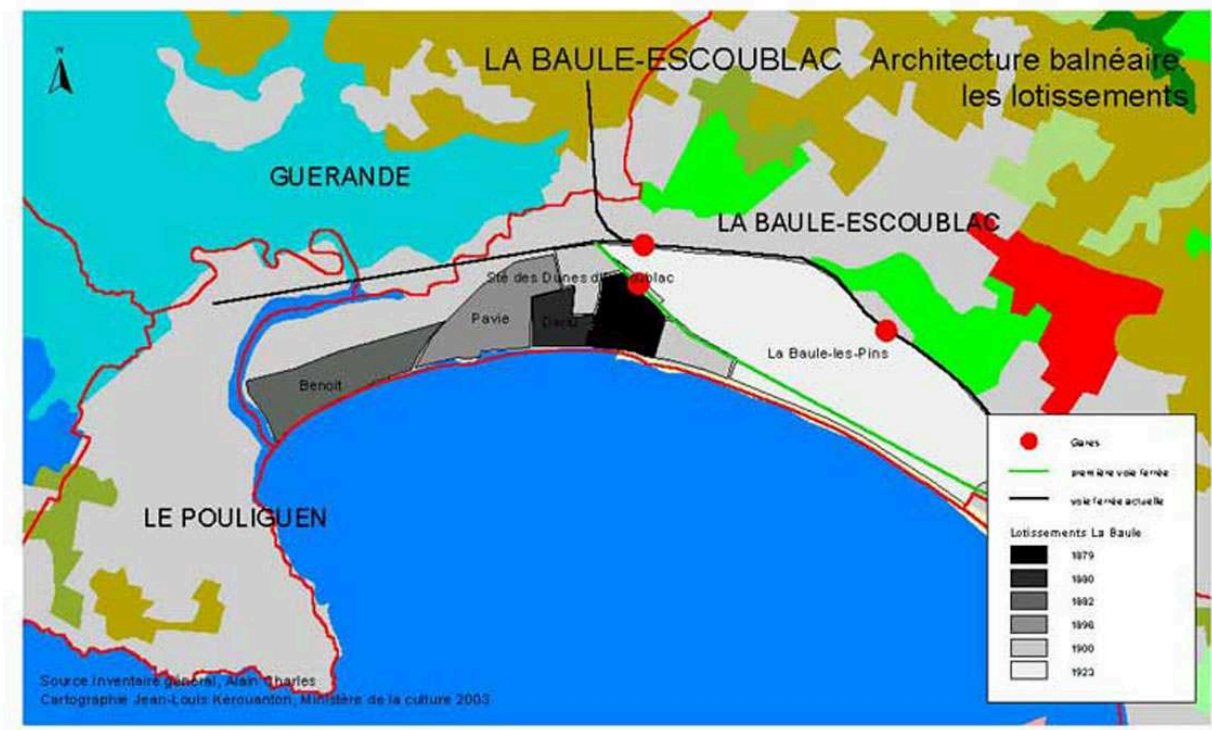

La Baule-Escoublac. Chronologie des édifices repérés. Répartition par quantiles, carrés de $250 \mathrm{~m}$. Source Inventaire général, Alain Charles. Base de données, état 2002.

Cartographie J.-L. Kerouanton (c) Inventaire général, ADAGP, 2003.

1 L'inventaire du patrimoine architectural balnéaire de la Baule a été réalisé par Alain Charles sous la direction scientifique du service régional de l'inventaire des Pays de la Loire. Les trois cartes qui suivent n'ont d'autre ambition que d'indiquer l'ampleur de la recherche et son intérêt pour la connaissance du territoire balnéaire. 
Figure 2

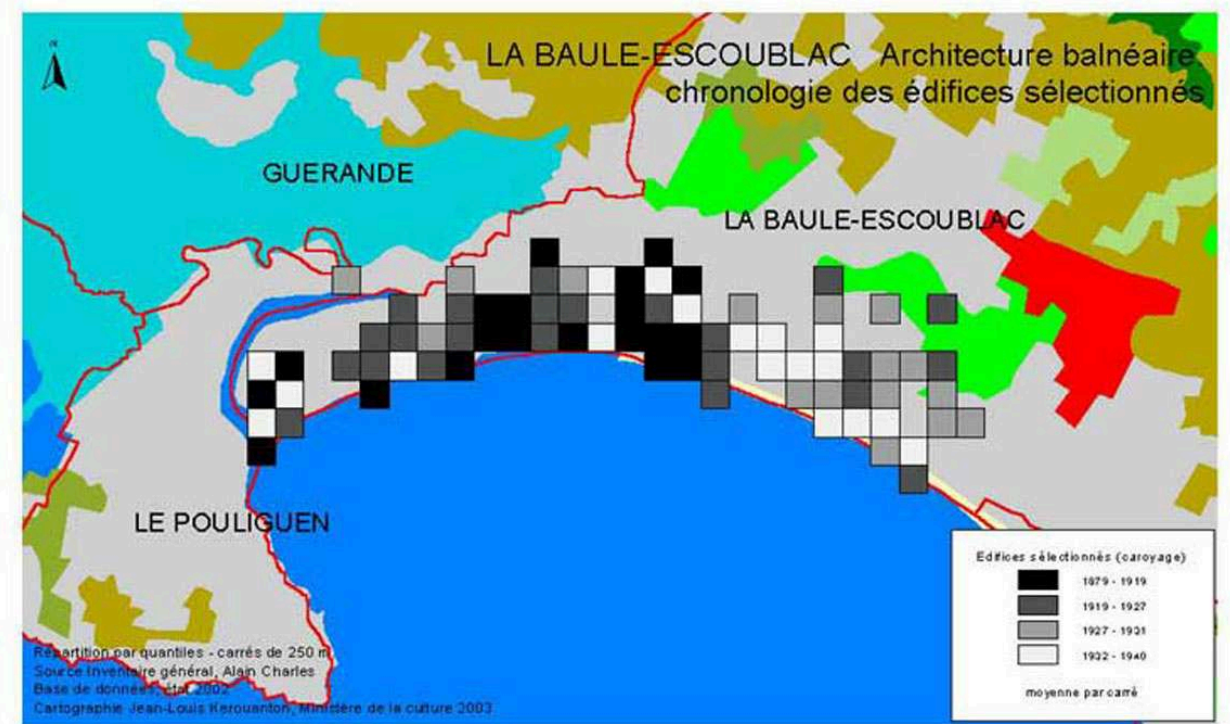

La Baule-Escoublac. Chronologie des édifices sélectionnés. Répartition par quantiles, carrés de $250 \mathrm{~m}$. Source Inventaire général, Alain Charles. Base de données, état 2002.

Cartographie J.-L. Kerouanton (c) Inventaire général, ADAGP, 2003

Ce sont en effet 2155 unités architecturales qui ont été repérées selon les normes de l'Inventaire général (fig. $\mathbf{n}^{\circ} \mathbf{1}$ ) ; l'étude a donné lieu à une sélection, et une présentation plus approfondie de 339 bâtiments (fig. $\mathbf{n}^{\circ} 2$ ) ou ensembles qui, depuis les années 1880 , fondatrices du premier lotissement jusqu'aux constructions des années 1950, permet d'illustrer l'éclectisme particulier de l'architecture bauloise (fig. $\mathbf{n}^{\circ} \mathbf{3}$ ). 
Figure 3

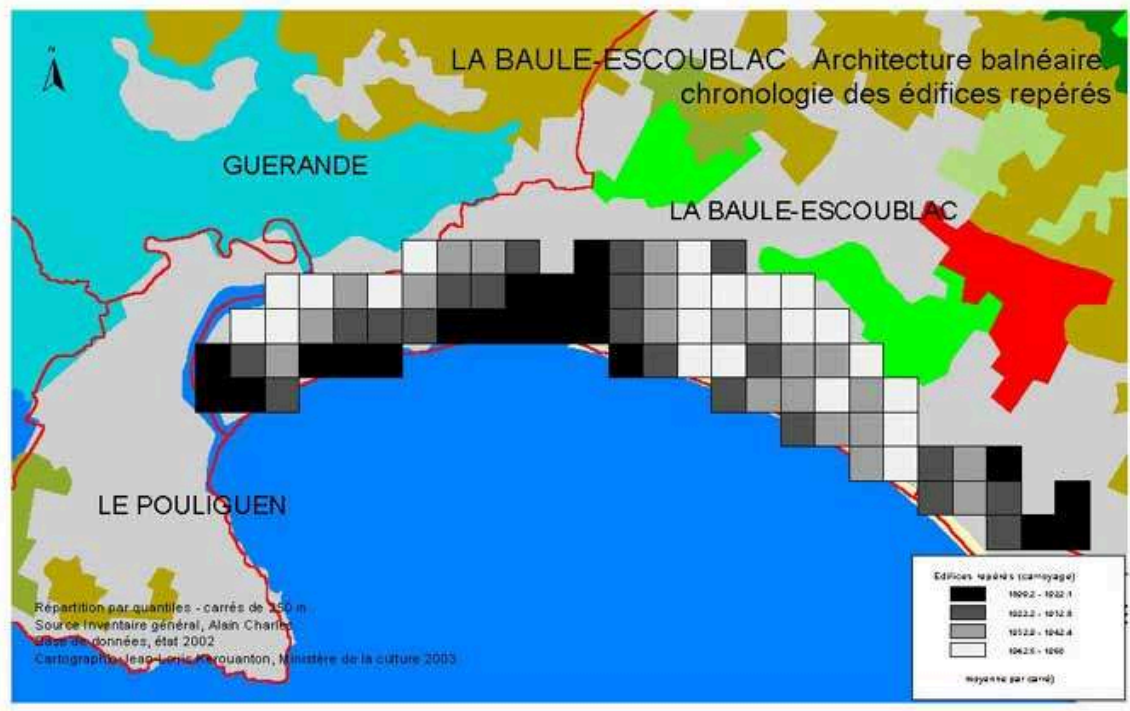

La Baule-Escoublac. Les lotissements. Source Inventaire général, Alain Charles.

Cartographie J.-L. Kerouanton @ Inventaire général, ADAGP, 2003.

Figure 4

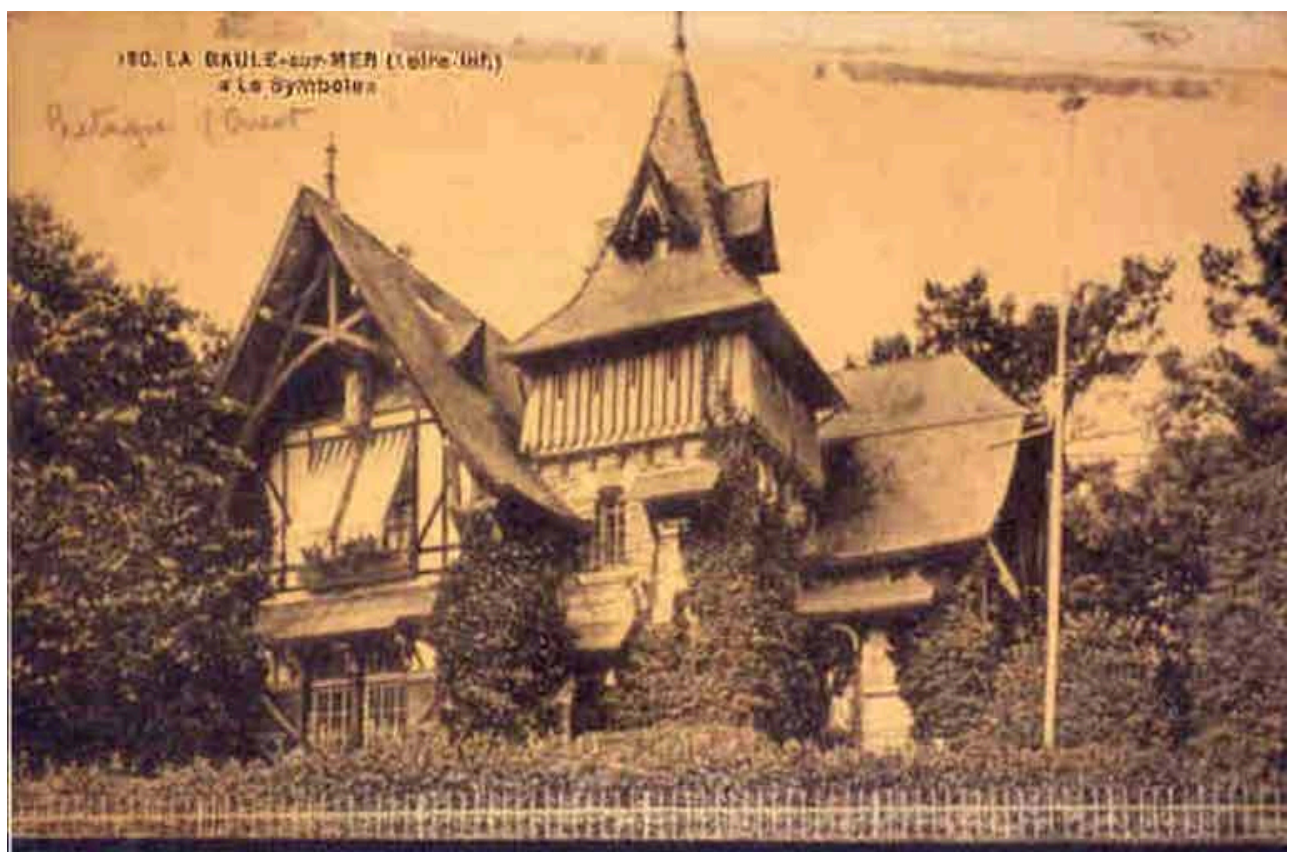

La Baule. Villa Symbole. Carte postale, s.d. [1 ${ }^{\mathrm{er}}$ quart XXe s.]. Coll. Part.

Repro. B. Toulier @ Droits réservés.

Le pittoresque néo-normand ou breton de la fin du XIXe siècle est représenté dès 1881 par la villa Symbole, face à la première gare de chemin de fer. Peu d'art nouveau, mais dès 1910 du néo-basque puis dans les années 1920 et 1930, certains édifices dessinés par 
un Grave ou un Dattessen, avec des éléments "paquebots " amènent tout naturellement à l'art déco, voire au mouvement moderne avec La Colline, par René Perrey en 1926.

Figure 5

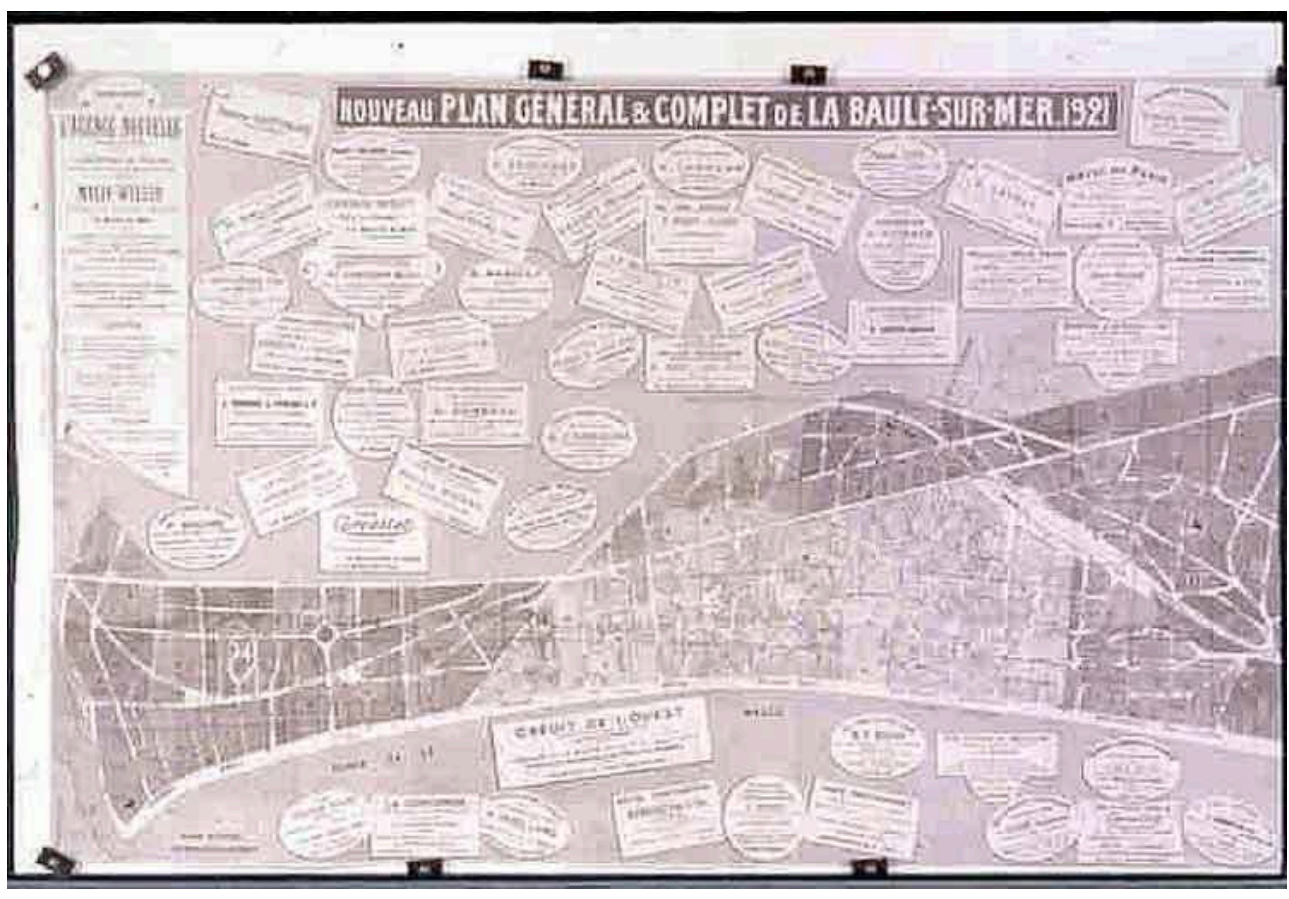

Plan général de La Baule. 1921. Etat des lotissements.

Repro. B. Toulier (c) Droits réservés.

4 La villa Symbole (fig. $\mathbf{n}^{\circ}$ 4) a bel et bien représenté jusqu'au début du XXe siècle un élément publicitaire fort de la station : face à la gare, c'était l'ouverture de l'ensemble de la pinède jusqu'à la mer, sur les terrains tout d'abord du lotissement Hennecart à partir de 1879, bientôt suivi vers l'ouest jusqu'au Pouliguen par les lotissements Darlu en 1880 et Benoit en 1882. En 1896, Pavie, puis surtout en 1900 la nouvelle Société des Dunes d'Escoublac complètent l'emprise de toute la pinède occidentale.

5 Il faut attendre 1923 pour que le grand lotissement de la Baule-les Pins (fig. $\mathbf{n}^{\circ}$ 5), avec sa nouvelle gare particulière le long de la voie ferrée détournée par le nord permette la conquête de l'ensemble du territoire dunaire vers l'est, jusqu'au contact de Pornichet. Si le pittoresque des allées ombragées sous les pins y est toujours de mise, la mise en place des avenues vers la mer, axée autour d'une nouvelle place circulaire, la place des Palmiers à mi-chemin de la gare, donne une nouvelle monumentalité à la station.

INDEX

Mots-clés : La Baule, Alain Charles, Grave, Dattessen, René Perrey, Pouliguen, Pavie, Escoublac 


\section{AUTEUR}

\section{JEAN-LOUIS KEROUANTON}

Chercheur au service régional de l'Inventaire, direction régionale des affaires culturelles des Pays-de-la-Loire - jean-louis.kerouanton@culture.gouv.fr 